\title{
PENYUSUNAN NERACA DAN LAPORAN ARUS KAS DI YAYASAN MASJID AL FATAH COMAL PEMALANG SESUAI PSAK NO.45
}

\author{
${ }^{1}$ Jilma Dewi Ayu Ningtyas, S.Pd. M.Si., ${ }^{2}$ Nor Rahayu \\ Politeknik Pusmanu
}

\begin{abstract}
Public sector accounting used by public institutions as a means of accountability to the public. Institutional public areas include government non-profit organizations and non-governmental non-governmental organizations. exp (foundations, non-governmental organizations, religious organizations, political organizations, etc.)The mosque is one of the nonprofit organizations in the religious field, in accordance with PSAK 45 on Nonprofit Organizations, that nonprofit organizations should also and are entitled to make financial reports and report to users of financial statements (Andarsari, 2016). The purpose of this study is to prepare a statement of financial position and cash flow statement in accordance with PSAK No. 45 at Masjid Al Fatah Comal Pemalang Foundation. The research object is Al Fatah mosque foundation which is located in Purwosari Village RT 02 RW 08 District Comal, Regency Pemalang. The research method used is observation, interview and documentation with descriptive analysis. The output of this research is in the form of financial report of Masjid Al Fatah Comal Pemalang Foundation in accordance with PSAK No. 45 and shows the balance sheet position in balance state amounting to $\mathrm{Rp} 1,362,568,000$, - and the cash flow statement shows the remaining unused cash of $\mathrm{Rp} 11,133,000$. The researcher's suggestion in the preparation of financial statements needs to be followed up, because the financial information can be known in detail and to know the development of the mosque's foundation every year. and should use cash basis method to make it easier.
\end{abstract}

Keywords : Financial Statements, Nonprofit Organizations, PSAK No.45

Correspondence to : jilmadewi@gmail.com, norrahayu71@gmail.com

\begin{abstract}
ABSTRAK
Akuntansi sektor publik adalah akuntansi yang dipakai oleh lembaga-lembaga publik sebagai alat pertanggung jawaban kepada publik. Secara kelembagaan wilayah publik antara lain meliputi organisasi nirlaba pemerintahan dan organisasi nirlaba non-pemerintahan meliputi organisasi sukarelawan, rumah sakit, sekolah tinggi dan universitas, serta organisasi-organisasi non pemerintahan lainnya (yayasan,lembaga swadaya masyarakat, organisasi keagamaan, organisasi politik, dan lain sebagainya). Masjid merupakan salah satu organisasi nirlaba dalam bidang keagamaan, sesuai dengan Pernyataan Standar Akuntansi Keuangan (PSAK) 45 tahun 2015 tentang Organisasi nirlaba, bahwa organisasi nirlaba juga harus dan berhak untuk membuat laporan keuangan dan melaporkan kepada para pemakai laporan keuangan (Andarsari,2016). Tujuan dari penelitian ini adalah untuk menyusun laporan posisi keuangan dan laporan arus kas yang sesuai dengan PSAK No. 45 di Yayasan Masjid Al Fatah Comal Pemalang. Obyek penelitian adalah yayasan masjid Al Fatah yang beralamat di Desa Purwosari RT 02 RW 08 Kecamatan Comal, Kabupaten Pemalang. Metode penelitian yang digunakan adalah observasi, wawancara dan dokumentasi dengan analisis deskriptif
\end{abstract}


Hasil output penelitian ini berupa laporan keuangan Yayasan Masjid Al Fatah Comal Pemalang yang sesuai dengan PSAK No. 45 dan menunjukan laporan posisi keuangan (neraca) dalam keadaan balance yaitu sebesar Rp 1.362.568.000,- dan pada laporan arus kas menunjukan sisa kas yang belum digunakan sebesar Rp 11.133.000,-. Saran peneliti dalam hal penyusunan laporan keuangan perlu ditindaklanjuti, karena agar informasi keuangan dapat diketahui secara detil serta untuk mengetahui perkembangan yayasan masjid setiap tahunnya. dan sebaiknya menggunakan metode basis kas (cash basic) agar memudahkan.

Kata kunci : Laporan Keuangan, Organisasi Nirlaba, PSAK No.45

Korspondensi :jilmadewi@gmail.com,norrahayu71@gmail.com

\section{PENDAHULUAN / INTRODUCTION}

Organisasi nirlaba didefinisikan sebagai sebuah organisasi yang tidak bertujuan mencari laba misalnya organisasi keagaaman, yayasan atau lembaga pendidikan. Organisasi tersebut juga membutuhkan informasi akuntansi seperti halnya organisasi yang bertujuan mencari laba. Walapun organisasi semacam ini tidak mencari laba, namun mereka tetap berurusan dengan keuangan karena mereka harus mempunyai anggaran, membayar tenaga kerja, membayar biaya utilitas seperti listrik, telepon, air serta urusan-urusan keuangan lainnya. Semua hal tersebut berkaitan dengan akuntansi

Masjid merupakan salah satu organisasi nirlaba dalam bidang keagamaan, sesuai dengan Pernyataan Standar Akuntansi Keuangan (PSAK) 45 tahun 2015 tentang Organisasi nirlaba, bahwa organisasi nirlaba juga harus dan berhak untuk membuat laporan keuangan dan melaporkan kepada para pemakai laporan keuangan (Andarsari,2016). Masjid harus membuat laporan keuangan yang akuntabilitas dan memberikan informasinya kepada para pemakai laporan keuangan tersebut yaitu para donatur masjid. Untuk dapat membuat laporan keuangan dana masjid dengan akurat dibutuhkan penerapan akuntansi, dan peranan akuntansi disini adalah memperlancar manajemen keuangan dalam fungsinya sebagai alat perencanaan, pengawasan dan pengambilan keputusan.

Penyusunan laporan keuangan masjid masih dilakukan secara sederhana. Laporan keuangannya meliputi penerimaan dan pengeluaran kas tanpa merinci sumber dana penerimaan dan pengeluaran kas. Selain itu laporan keuangannya tidak memperlihatkan jumlah dan nilai aset yang dimiliki, sehingga banyak kasus hilangnya aset masjid karena kelemahan sistem penyusunan laporan keuangan tersebut. Dari latar belakang tersebut di atas, maka penulis tertarik untuk melakukan penelitian

Tujuan penelitian ini adalah untuk mengetahui laporan posisi keuangan (neraca) dan laporan arus kas pada Yayasan Masjid Al Fatah Comal Pemalang yang sesuai dengan PSAK No.45

\section{TINJAUAN PUSTAKA}

\section{Pengertian Akuntansi sektor publik}

Akuntansi sektor publik menurut Renyowijoyo (2013: 1) adalah sistem akuntansi yang dipakai oleh lembaga-lembaga publik sebagai salah satu alat pertanggungjawaban kepada publik. Ruang lingkupnya meliputi badan-badan pemerintahan (pemerintah pusat, pemerintah daerah, dan unit-unit kerja pemerintah), 
organisasi sukarelawan, rumah sakit, perguruan tinggi dan universitas, yayasan, lembaga swadaya masyarakat, organisasi keagamaan, organisasi politik, dan sebagainya

\section{Organisasi Nirlaba}

Karakteristik entitas nirlaba berbeda dengan entits bisnis, perbedaan utama yang mendasar terletak pada cara entitas nirlaba memperoleh sumber daya yang dibutuhkan untuk melakukan berbagai aktivitas operasinya. Organisasi nirlaba memperoleh sumber daya dari pemberi sumber daya yang tidak mengharapkan pembayaran kembali atau manfaat ekonomik yang sebanding dengan jumlah sumber daya yang diberikan (PSAK 45, 2015)

Berikut istilah yang digunakan dalam laporan keuangan organisasi nirlaba menurut PSAK 45 tahun 2015 :

1. Pembatasan permanen adalah pembatasan penggunaan sumber daya yang ditetapkan oleh pemberi sumber daya yang tidak mengharapkan pembayaran kembali agar sumber daya tersebut dipertahankan secara permanen, tetapi entitas nirlaba diizinkan untuk menggunakan sebagian atau semua penghasilan atau manfaat ekonomik lain yang berasal dari sumber daya tersebut.

2. Pembatasan temporer adalah pembatasan penggunan sumber daya oleh pemberi sumber daya yang tidak mengharapkan pembayaran kembali yang menetapkan agar sumber daya tersebut dipertahankan sampai dengan periode tertentu atau sampai dengan terpenuhinya keadaan tertentu.

3. Sumber daya terikat adalah sumber daya yang penggunanya dibatasi untuk tujuan tertentu oleh pemberi sumber daya yang tidak mengharapkan pembayaran kembali. Pembatasan tersebut dapat bersifat permanen atau temporer.

4. Sumber daya tidak terikat adalah sumber daya yang penggunanya tidak dibatasi untuk tujuan tertentu oleh pemberi sumber daya yang tidak mengharapkan pembayaran kembali.

\section{Laporan keuangan entitas nirlaba}

Laporan keuangan berdasarkan PSAK no. 45

a. Laporan Posisi Keuangan

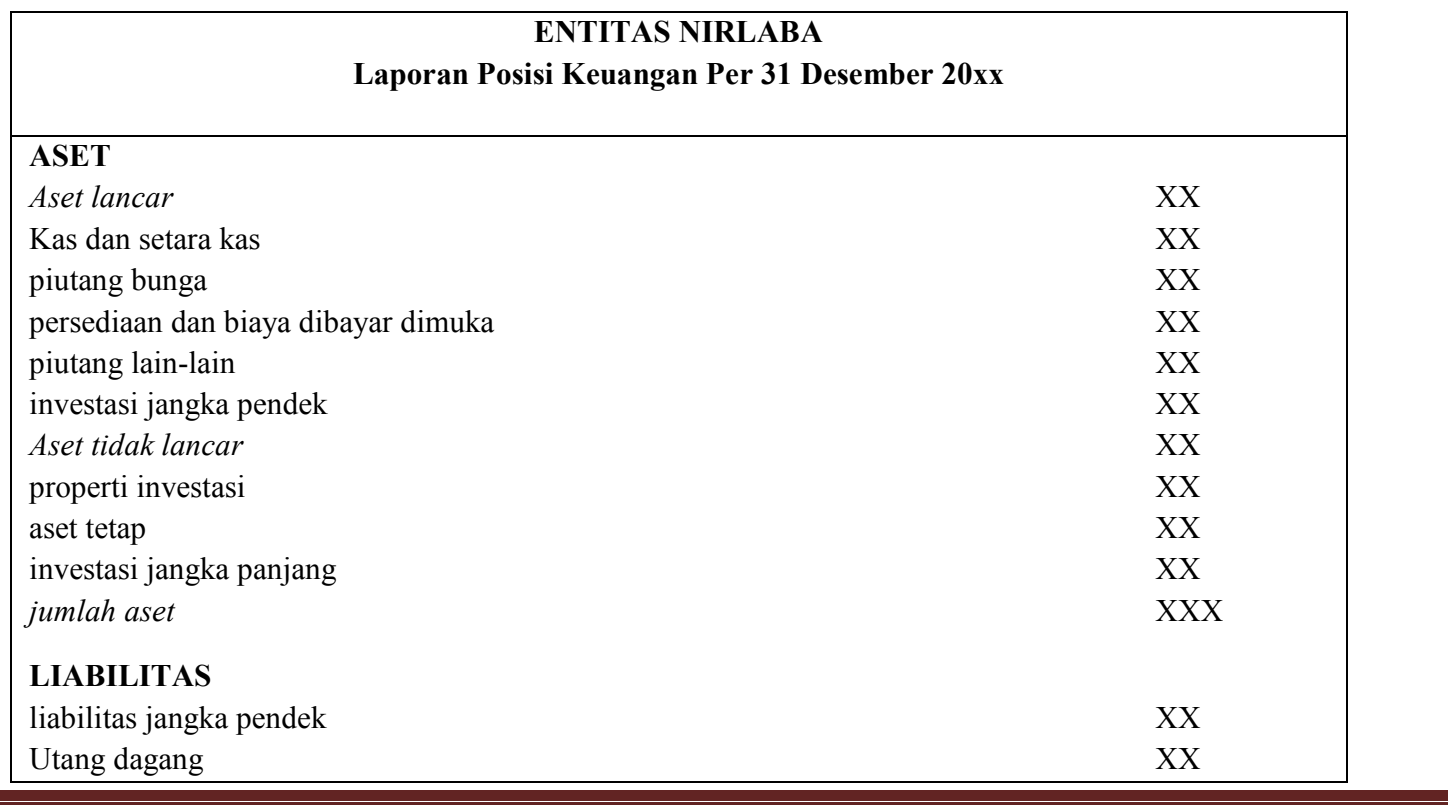


Balance Vol. XVI No. 1 | Januari 2019

\begin{tabular}{|ll}
\hline Pendapatan diterima dimuka yang dapat dikembalikan & $\mathrm{XX}$
\end{tabular}

Utang lain-lain $\quad$ XX

Utang Wesel $\quad$ XX

Liabilitas Jangka Panjang $\quad$ XX

Kewajiban tahunan $\quad X X$

Utang jangka panjang $\quad \mathrm{XX}$

Jumlah liabilitas $\quad \mathrm{XX}$

\section{ASET NETO}

Tidak terkait

$\mathrm{XX}$

Terkait Temporer (catatan B) $\quad$ XX

Terkait permanen (Catatan C) XX XX

Jumlah aset neto $\quad \mathrm{XX}$

Jumlah Liabilitas dan aset neto $\quad$ XXX

b. Laporan Arus Kas

ENTITAS NIRLABA

Laporan arus kas untuk tahun berakhir pada 31 Desember 20XX

AKTIVITAS OPERAS

Kas dari pendapatan Jasa

Kas dari pemberi sumber daya $\quad$ XX

Kas dari Piutang lain-lain $\quad X X$

$\begin{array}{ll}\text { Bunga dan deviden yang diterima } & X X\end{array}$

$\begin{array}{ll}\text { Penerimaan lain-lain } & X X\end{array}$

$\begin{array}{ll}\text { Bunga yang dibayarkan } & X X\end{array}$

Kas yang dibayarkan kepada karyawan dan supplier $\quad$ (XX)

Utang lain-lain yang dilunasi $\quad$ (XX)

Kas neto yang diterima (digunakan) untuk aktivitas operasi $\quad$ XXX

AKTIVITAS INVESTASI

Ganti Rugi dari asuransi kebakaran $\quad$ XX

$\begin{array}{ll}\text { Pembelian Peralatan } & \text { (XX) }\end{array}$

$\begin{array}{ll}\text { Penerimaan dari penjualan investasi } & X X\end{array}$

Pembelian investasi $\quad$ (XX)

Kas Neto yang diterima (digunakan) untuk aktivitas investasi $\quad$ XXX

$\mathrm{XX}$

AKTIVITAS PENDANAAN

penerimaan dari kontribusi berbatas dari

Investasi dalam endowment

$X X$

Investasi dalam endowment berjangka $\quad$ XX

$\begin{array}{ll}\text { Investasi bangunan } & X X\end{array}$

$\begin{array}{ll}\text { Investasi perjanjian tahunan } & X X\end{array}$

Aktivitas pendanaan lain :

Bunga dan deviden berbatas unuk reinvestasi $\quad$ XX

Pembayaran kewajiban tahunan 


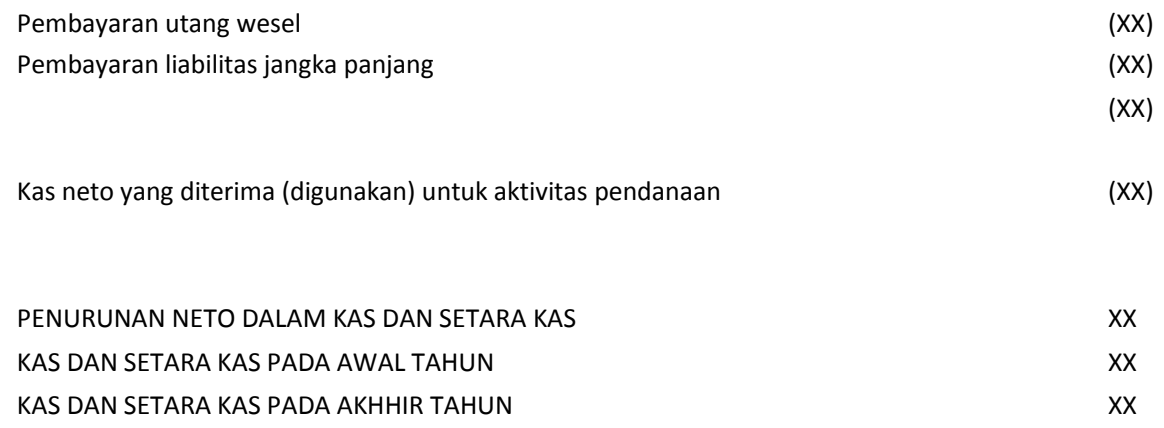

\section{METODE PENELITIAN / METHODS}

Penelitian ini mengambil objek Yayasan Masjid Al-Fatah yang beralamatkan di Desa Purwosari RT 02 Rw 08 Kecamatan Comal, Kabupaten Pemalang. Sumber data yang digunakan adalah data primer yang dikumpulkan dengan metode observasi, wawanvara dan dokumentasi. Sedangkan untuk analisis data menggunakan cara analisis deskriptif.

\section{HASIL PENELITIAN DAN}

\section{PEMBAHASAN / RESULTS AND DISCUSSION}

Berdasarkan metode pengumpulan data yang dilakukan maka hasil pengumpulan data yang diperoleh penulis yaitu sebagai berikut :

a. Catatan penerimaan dan pengeluaran kas Yayasan Masjid Al Fatah Comal Pemalang masih sederhana.

b. Wancara dengan informan untuk data aset yang dimiliki

c. Transaksi yang terjadi selama periode tahun 2016
Peneliti menyusun laporan posisi keuangan dan laporan arus kas menggunakan tahapan sebagai berikut :

1. Tahap perencanaan

Pada tahap ini peneliti melakukan pencatatan bukti-bukti transaksi di Yayasan Masjid Al-fatah Comal Pemalang. Transaksi yang dicatat dibuktikan dengan faktur, bukti transfer, nota kuitansi dan lain-lain.

2. Tahap pengikhtisaran

Pada tahap ini peneliti membuat jurnal dan buku besar untuk selanjutnya membuat neraca saldo

3. Tahap pelaporan

Pada tahap ini peneliti menyusun laporan posisi keuangan dan laporan arus kas sesuai dengan PSAK 45

Berikut laporan posisi keuangan dan laporan arus kas Yayasan Masjid Al-Fatah yang sudah disesuaikan dengan PSAK 45 dengan keadaan yang ada dilapangan 
Laporan Posisi Keuangan (Neraca) Yayasan Masjid Al- Fatah Comal Pemalang

\begin{tabular}{|lc|}
\hline & $\begin{array}{c}\text { LAPORAN POSISI KEUANGAN } \\
\text { YAYASAN AL FATAH COMAL PEMALANG } \\
\text { PERIODE TAHUN 2016 }\end{array}$ \\
Aset & \\
Aset lancar & Rp.18.883.000,-- \\
Kas & Rp.30.000.000,- \\
Perlengkapan & Rp.48.883.000,-- \\
Total Aset Lancar & Rp.1.215000.000,- \\
Aset tetap & Rp.100.000.000,-- \\
Tanah & Rp.1.315.000,-) \\
Bangunan & Rp.1.313.685.000,- \\
Ak.Penyusutan & Rp.1.362.568.000,- \\
Total Aset tetap & \\
Total Aset & \\
Liabilities & Rp.0,- \\
Total Liabilities & Rp.1.351.435.000,- \\
Aset Neto & Rp.11.133.000,- \\
Total Aset Neto & \\
Penurunan aset neto & \\
Total liabilities dan Aset Neto Rp.1.362.568.00,- \\
\hline
\end{tabular}

Laporan Arus Kas Yayasan Masjid Al-Fatah Comal Pemalang

\begin{tabular}{|c|c|c|}
\hline \multicolumn{3}{|c|}{$\begin{array}{l}\text { LAPORAN ARUS KAS } \\
\text { YAYASAN AL FATAH COMAL PEMALANG } \\
\text { PERIODE TAHUN } 2016\end{array}$} \\
\hline $\begin{array}{l}\text { AKTIVITAS OPERASI } \\
\text { Kas dari penyumbang } \\
\text { Kotribusi perbaikan masjid: } \\
\text { Beban rehab } \\
\text { Beban perbaikan bedug } \\
\text { Beban pemasangan pintu } \\
\text { AKTIVITAS PENDANAAN } \\
\text { Aktivitas pendanaan lain: } \\
\text { Beban listrik } \\
\text { Beban kebersihan } \\
\text { Pembelian } \\
\text { Kenaikan/Penurunan kas }\end{array}$ & $\begin{array}{l}\text { Rp. } \\
\text { (Rp. } \\
\text { (Rp. } \\
\text { (Rp. } \\
\text { Rp. }\end{array}$ & $\begin{array}{r}88.236 .000,- \\
\\
54.967 .000,-) \\
7.900 .000,-) \\
9.725 .000,-) \\
15.644 .000,-\end{array}$ \\
\hline
\end{tabular}

\section{KESIMPULAN, KETERBATASAN CONCLUSSION Kesimpulan}

Kesimpulan yang dapat diambil dari Penelitian ini adalah sebagai berikut :

1. Penerimaan dan pengeluaran kas Yayasan Masjid Al Fatah Comal Pemalang menggunakan metode pencatatan basis kas (cash basic).

2. Model penyusunan laporan keuangan pada Yayasan Masjid Al Fatah Comal Pemalang sesuai PSAK No. 45 menunjukan bahwa hasil dari Laporan Posisi Keuangan dalam keadaan balance, yaitu sebesar Rp.1.362.568.000,-, dan pada Laporan Arus Kas menunjukan angka sebesar Rp.11.133.000,-.

\section{Saran}

Saran yang dapat diberikan adalah sebagai berikut :

1. penyusunan laporan keuangan yang sesuai dengan yayasan atau organisasi masjid yaitu 
Balance Vol. XVI No. 1 | Januari 2019

berdasarkan PSAK No.45 dan sebaiknya menggunakan metode basis kas (cash basic) agar memudahka

2. penyusunan laporan keuangan perlu ditindaklanjuti, karena agar informasi keuangan dapat diketahui secara detil serta untuk mengetahui perkembangan yayasan masjid setiap tahunnya.

\section{DAFTAR PUSTAKA / BIBLIOGRAPHY}

Andarsari, Pipit Rosita. 2016. Laporan Keuangan Organisasi Nirlaba. Jurnal Ekonomi Universitas Kadiri. Vol.1 No. 2

Ikatan Akuntansi Indonesia. 2015. PSAK No. 45 Revisi 2015. Jakarta: Ikatan Akuntansi Indonesia

Renyowijoyo, Muindro 2013. Akuntansi Sektor Publik : Organisasi Non Laba Edisi 3. Jakarta : Mitra Wacana Media 